\title{
Educação e comunicação: textos, imagens e redes
}

\author{
Profa. Dra. Maria Cristina Castilho Costa \\ Livre-docente em Ciências da Comunicação pela Escola de Comunicações e Artes da Universidade \\ de São Paulo. Professora associada da Universidade de São Paulo, presidente da Comissão de \\ Pesquisa da ECA/USP, coordenadora do Curso de Especialização Lato Sensu Educomunicação: \\ comunicação, mídias e educação. Coordenadora do Núcleo de Pesquisa em Comunicação e Censura \\ da USP (NPCC) e do Projeto Temático Comunicação e Censura - Análise teórica e documental de \\ processos censórios a partir do Arquivo Miroel Silveira da ECA/USP, com apoio da FAPESP. \\ E-mail: criscast@usp.br
}

Resumo: O texto sustenta a ideia de que as redes sempre estiveram presentes no desenvolvimento dos meios de comunicação. Entretanto, a partir da segunda metade do século $X X$, um novo modelo de rede se tornou realidade: flexível, multidirecional, interativa e não centralizada. A rede de comunicação por computadores tem se tornado importante na educação formal e não formal e tem se constituído um veículo de difusão, relacionamento e informação entre educadores. Por isso, mais do que nunca, é importante que professores e pesquisadores participem da rede, conheçam-na e possam orientar os usuários a também fazerem isso da melhor forma. A educação para os meios lhe dará as garantias de um uso consciente e crítico.

Palavras-chave: Redes, imagens, textos, educação para os meios.
Abstract: The text puts forward the idea that networks have always been present in the development of the means of communication. However, as from the second half of the twentieth century, a new model of network has become a reality: a network which is flexible, multidirectional, interactive, and decentralized. The communication network by computers has become important in formal and non-formal education and has turned into a vehicle for diffusion, connection and information among educators. Therefore, it is vital, now more than ever, that teachers and researchers participate in the network, get to know it, and are able to guide the users on how best to use it themselves. Education for the means of communication will ensure they can use it consciously and critically.

Keywords: Networks, images, texts, education for the means of communication.

Educar é impregnar de sentido o que fazemos a cada instante.

Paulo Freire

Os processos de comunicação sempre estiveram ligados à ideia de rede entre pessoas, leitores, ouvintes, espectadores, usuários. Desde a invenção da escrita, temos convivido com a certeza da autonomia das mensagens, que passaram a se disseminar e a alcançar um público cada vez maior num lastro crescente de tempo e espaço. Os meios de comunicação, desde as tabuinhas de cerâmicas utilizadas na antiguidade, passando pelos papiros e, finalmente, pelo papel, cada vez mais ajudavam o acúmulo de informação e o trânsito por essas trilhas que se tornaram cada dia mais complexas. Seguindo o princípio da distribuição geográfica, essas redes assumiam uma arquitetura radicular, semelhante ao 
comunicação \& educação • Ano XVII • número 2 • jul/dez 2012

desenho da raiz de uma árvore, com um ponto central emissor e ramificações se dispersando por nós e embocaduras. Esse desenho centralizado estabelece uma forte hierarquização da rede, privilegiando o centro emissor e estabelecendo uma significativa dependência em relação ao meio onde se instala - a comunicação é tão mais rápida e fiel quanto mais próximo o receptor está da fonte. Assim se formaram as redes de telégrafos, de rádio e de televisão.

As redes de comunicação, por onde trafegam não só mensagens, mas também produtos e pessoas, à medida que se multiplicaram, passaram a exibir sua fragilidade, especialmente naquelas situações em que o controle das informações se tornou tão importante quanto a agilidade e rapidez na distribuição das mensagens.

Exemplos de evidente fragilidade foram as redes de espionagem criadas durante a Guerra Fria, quando a queda de um informante colocava em cheque todo o sistema de informação. Essa vulnerabilidade levou o engenheiro polonês Paul Baran, na década de 1960, a propor à Força Aérea norte-americana um protótipo revolucionário para as redes de comunicação: uma trama flexível, multidirecional e descentralizada, por onde se partilhasse informação de forma não hierarquizada - uma rede de desenho rizomático. Com base nessas orientações, foi criada a primeira rede por computadores, por Joseph Licklider, do Escritório de Tecnologia de Processamento de Informações (IPTO). A partir de então e nas duas décadas seguintes, as redes nesse novo desenho se multiplicaram pelo mundo, criando, efetivamente, uma malha mundial de comunicação.

O resultado foi uma arquitetura de rede que, como queriam seus inventores, não pode ser controlada a partir de nenhum centro e é composta por milhares de redes de computadores autônomos com inúmeras possibilidades de conexão, contornando barreiras eletrônicas ${ }^{1}$.

Manuel Castells define as redes de comunicação como conjuntos de nós interconectados, cuja topologia define as distâncias entre seus usuários². O fluxo de informação entre eles, por sua vez, depende de uma hierarquia definida pela arquitetura da rede, que estabelece o trânsito dos dados no tempo e no espaço. São estruturas abertas que se podem expandir de forma ilimitada, desde que os usuários compartilhem os mesmos códigos de comunicação. Por isso, as redes implicam uma política interna, ou seja, uma distribuição de poder.

As redes são criadas para diversas finalidades concretas, como circulação financeira e investimento de capitais, gestão política, sistemas de comunicação midiática, como rádio e televisão, e formação de arquivos e acervos públicos - e, também, tráfico de drogas e outras formas de organização social, como rebeliões e ativismo político. Como toda a sociedade se organiza através dessas redes, elas interferem diretamente na atuação e na ação concreta dessa mesma sociedade.

1. CATELLS, Manuel. A sociedade em rede. São Paulo: Paz e Terra, 1999. p. 26.

2. Id., p. 498

\section{REDES SOCIAIS}

As chamadas redes sociais, porém, são redes especialmente criadas, do ponto de vista de seus usuários, para a sociabilidade, para a interação entre pessoas nelas conectadas. De uma maneira geral, são programas de comunicação por 
computador em que cada usuário se conecta a partir de um convite pessoal, preenchendo um cadastro individual no qual traça um perfil de seus gostos, tendências, hábitos, informações pessoais, imagens, parentescos, participação institucional e interesses que vão de relacionamentos afetivos a jogos e entretenimento. O Facebook, criado por Mark Zuckerberg, é expressão inequívoca da mentalidade da sociedade contemporânea - globalizada, individualizada, tecnicista e cada vez mais mediatizada ${ }^{3}$.

Criando uma nova cultura de sociabilidade, entretenimento, enciclopedismo, participação social, publicidade e difusão de informações, as redes sociais como Facebook, Orkut, Twitter, YouTube e My Space se transformaram em uma verdadeira febre entre os usuários da Internet. E, para nós, autores, editores, colaboradores, conselheiros e leitores da Revista Comunicação \& Educação, é importante saber que uma parte significativa das mensagens que transitam por elas é dedicada às questões da educação na atualidade, à vida dos educadores, às campanhas por educação, à divulgação de pensamentos e teorias de importantes pedagogos. Desde sites de divulgação de instituições educativas até a troca de informações entre professores, passando por campanhas sustentadas por movimentos sociais ligados a escolas, educadores e desenvolvimentos político e social; grupos de discussão entre alunos e ex-alunos; relacionamento entre professores e estudantes em diferentes níveis escolares; divulgação de seminários, congressos e lançamentos de livros, além de outras iniciativas individuais e coletivas, públicas e privadas, nacionais e internacionais, ocupam muitos megabits das redes de comunicação.

A Revista Comunicação \& Educação, ao longo dos seus vinte anos de existência, tem alertado para a necessidade de os educadores conhecerem, analisarem e utilizarem as mídias digitais e a Internet em suas atividades pedagógicas. Argumentamos a favor dessa ideia com a justificativa de que estudantes devem se familiarizar com as novas mídias e com sua interatividade; que a maioria das profissões, hoje, exige esse conhecimento; que a rede de computadores acumula conhecimentos atualizados e globalizados; que as linguagens multimídias são cada vez mais utilizadas e necessárias. Mas, neste número, é o espaço que o tema "educação" vem conquistando nas redes sociais o nosso argumento.

São inúmeros os alertas para a necessidade de um aprimoramento das políticas públicas de educação; chamadas para a valorização do professor; críticas em relação ao descaso dos políticos para com a educação; teorias pedagógicas voltadas ao desenvolvimento social e humano e a expressão de uma opinião pública cúmplice dos educadores e daqueles que os defendem. Assim, as redes sociais abrem ao educador a oportunidade de trocar ideias, formular opiniões, divulgar sua experiência e conhecimento e atingir um público que cresce dia a dia, especialmente no Brasil. Somos o país com maior índice de uso das redes sociais na América Latina, e estima-se que mais de 70 milhões de pessoas se constituam em seus usuários, estando $63 \%$ deles entre 15 e 35 anos. Se esses índices não são suficientes para motivar o educador relutante, a qualidade das matérias que circulam na Internet certamente o convencerá. Mensagens como a frase que serve de epígrafe a este ensaio, atribuída a Paulo Freire e repercutida

3. Para saber mais sobre o assunto: COSTA, Maria Cristina Castilho. No que você está pensando? Redes sociais e sociedade contemporânea. Revista USP, São Paulo, v. 22, p. 86-99, 2012. 
comunicação \& educação • Ano XVII • número 2 • jul/dez 2012

em inúmeros sites e blogs de professores, pesquisadores e instituições educacionais, dão o tom do que se fala sobre educação nas redes sociais.

Quanto às resistências que ainda dificultam a utilização das redes sociais por educadores em suas atividades didáticas, lembramos que a educação para os meios é a área da interface entre comunicação e educação que mais colabora no sentido de conscientizar o usuário das implicações mercadológicas, publicitárias e manipuladoras das mídias, sejam elas analógicas ou digitais. Assim, trata-se não apenas de incluir as redes como recurso tecnológico na relação professor-aluno, ou de fazer das informações que por ela circulam referências no processo educativo, mas de fazer uso consciente e crítico de seu potencial comunicativo. Só não podemos desconhecer ou desconsiderar seu poder na atualidade. $\mathrm{O}$ número da Revista Comunicaşão \& Educaşão que ora apresentamos traz considerações importantes a esse respeito, mostrando que isso é necessário e possível.

Passemos agora à apresentação dos textos que se seguem, os quais complementam o convite que aqui fazemos para que a redes sociais sejam, cada vez mais, um espaço de educação e de educadores:

\section{ARTIGOS INTERNACIONAIS: DE EDUCAÇÃO PARA AS MÍDIAS ÀS TRADIÇÕES DO CORPO}

Neste número demos destaque aos artigos internacionais. Tendo recebido diversas colaborações de autores estrangeiros, julgamos oportuno ceder-lhes mais espaço para que nossos leitores pudessem conhecê-las. Começamos por um artigo muito importante, de autoria de David Buckingham, intitulado "Precisamos realmente de educação para os meios?", no qual o autor aborda as diferentes correntes teóricas que explicam as chamadas "novas mídias", algumas refletindo certo otimismo ideológico californiano, outras discutindo criticamente os diferentes usos das mídias digitais e da Internet. Considerando o bom desempenho com mídias digitais como resultado de competências culturais, habilidades sociais e conhecimento, Buckingham alerta para as persistentes desigualdades que se mantêm com a Web 2.0, colocando por terra qualquer visão determinista sobre a tecnologia.

O chileno Valerio Fuenzalida é o autor de "Educação para a comunicação televisiva", em que aborda o desenvolvimento de estudos e pesquisas latino-americanas envolvendo a televisão, os quais teriam sido responsáveis por sua introdução no currículo da educação formal. O artigo enfoca as transformações resultantes desses trabalhos, que implicaram, entre outras coisas, a compreensão da televisão como a mídia doméstica por excelência, ou seja, cuja recepção se dá em casa, junto à família, em meio à vida cotidiana. Discorrendo sobre as características da televisão enquanto mídia e sobre seu uso na escola, ele adverte: "Não basta introduzir as mídias nas atividades escolares, é preciso capacitar a família para ser mediadora entre elas e as crianças e jovens".

Um terceiro artigo internacional é de autoria da pesquisadora luso-francesa Graça dos Santos, que aborda a importância da voz na constituição da identidade individual e coletiva e na expressão do ser na sociedade. A partir do reconhecimento dessa importância, a autora ressalta, por consequência, também 
a importância do corpo. Para essa explanação ela usa o teatro, arte à qual se dedica tanto na prática como na pesquisa teórica. É a partir dele que considera a voz como o caminho de encontro consigo mesmo e com o outro.

\section{ARTIGOS NACIONAIS: DA EDUCAÇÃO PARA AS MÍDIAS À COMUNICAÇÃO CIENTÍFICA, CHEGANDO À ANÁLISE SEMIÓTICA DE LADY GAGA}

Temos três artigos nacionais neste número. Alexandra Bujokas de Siqueira também se dedica ao estudo da Educação para as Mídias, ou Media Literacy, defendendo a necessidade de uma visão crítica sobre os meios de comunicação, capaz de engendrar um leitor crítico, conforme proposta da UNESCO. Tal proposta, entretanto, envolve, além de uma atitude crítica e política, também um planejamento de caráter abrangente, englobando diferentes esferas do poder. Segundo a autora, o resultado dessa proposta será obter cidadãos letrados e conteúdos midiáticos de qualidade.

Cecília Cavalcanti é autora do artigo "A comunicação científica nos espaços de educação não formais", no qual aborda a crescente importância da divulgação científica através das mídias - especialmente, na atualidade, com o advento das mídias digitais. Segundo a autora, as novas tecnologias da comunicação não só desenvolvem a divulgação científica como a própria ciência, na medida em que possibilitam a pesquisa por grupos integrados pela rede de computadores.

Com base em diferentes autores que analisam a importância da imagem visual na cultura contemporânea, Luciana Coutinho Pagliarini de Souza e Maria Ogécia Drigo analisam a imagem de um ícone da atualidade - Lady Gaga. Passando por Roland Barthes e Umberto Eco, as autoras reafirmam a importância do estudo da leitura das imagens para proporcionar um olhar capaz de contemplar, discriminar e generalizar. Seu exercício em decodificar a imagem da estrela da música pop inglesa se apresenta como uma das possibilidades para alcançar esse objetivo.

\section{AINDA A IMAGEM - DEPOIMENTO DE BORIS KOSSOY}

Fotógrafo, pesquisador, autor e professor, Boris Kossoy deu seu depoimento à Revista Comunicação \& Educação. Hoje, a importância da imagem é algo que se sabe e se compreende, diz Kossoy, que escreveu inúmeros livros e artigos para nos ensinar que a imagem não é mera ilustração do texto, mas uma ação sobre a realidade e uma forma muito profunda de conhecimento sobre ela.

\section{EDUCAÇÃO PARA OS MEIOS NÃO SIGNIFICA APENAS ENTUSIASMO TECNOLÓGICO}

Gianna Cappello é a entrevistada deste número da Revista Comunicação \& Educação. A presidente da Associazione Italiana per l'Educazione ai Media e alla Comunicazione (MED) ressalta o aumento da importância da educação para 
comunicação \& educação • Ano XVII • número 2 • jul/dez 2012

os meios de comunicação em todo o mundo. Otimista com o fato, comenta, entretanto, que isso não significa, de maneira nenhuma, apenas entusiasmo com o uso da tecnologia.

\section{MÍDIAS AUDIOVISUAIS: TELENOVELAS E CINEMA}

Marcia Perecin Tondato, na seção Crítica, propõe-se a estudar as telenovelas brasileiras apresentadas nos últimos onze anos, construindo um trabalho interessante de referência que será útil para muitos estudiosos. Passando pelos principais títulos apresentados, a autora vai mostrando o que mudou na televisão, na sociedade e na recepção do veículo, até a telenovela se tornar um produto de consumo diferente daquele que a caracterizou nos seus primórdios, quando alcançava índices astronômicos de audiência. Uma nova sociedade, um novo espectador, uma nova realidade midiática exigem, também, uma telenovela diferente.

A estreia do filme Xingu, de Cao Hamburger, é o pretexto para Maria Ignês Carlos Magno abordar a imagem do índio na cinematografia brasileira. De Hans Staden, de Luis Alberto Pereira, passando por Caramuru, a invenção do Brasil, de Guel Arraes, chegando a Xingu, a autora mostra a difícil tarefa de se abordar o índio, seja de forma histórica ou como ficção.

\section{AINDA MAIS...}

Finalmente, dois livros foram resenhados nessa edição da Revista Comunicação \& Educação. O primeiro é a obra Chez Mme. Maigret, de Renata Pallottini, resenhada por Maria Cristina Castilho Costa, que procura mostrar como um leitor pode se tornar autor, apossando-se dos personagens pelos quais se apaixona.

O segundo é Gestão pública do ambiente e educação ambiental: caminhos e interfaces, de Carlos Frederico Loureiro, que Ismar de Oliveira Soares resenha, apontando para a obra como uma rica fonte para estudiosos da gestão comunicativa.

E, por falar em Gestão, a seção da revista que tem esse título apresenta o projeto de comunicação desenvolvido por Ana Cláudia Marigliani Bogner para o Programa de Mestrado em Comunicação e Práticas do Consumo da Escola Superior de Propaganda e Marketing, com o objetivo de torná-lo mais conhecido de seu público-alvo, fortalecendo seus objetivos e identidade.

Terminamos com uma nota poética - escolhida por Adílson Odair Citelli -, em que Agnaldo José Gonçalves se faz presente com versos de sua obra Vermelho, na qual, como uma boa metáfora sobre o conteúdo do presente número de nossa revista, aproxima a linguagem verbal da linguagem plástica e visual.

Espero que nossos leitores apreciem toda essa riqueza em letras, sons e imagens. 